SYLWIA JASKULA

PEDAGOGIUM Wyższa SzkoŁa Nauk SpoŁecznych w Warszawie

\title{
LESZEK KORPOROWICZ
}

UNIWERSYTET JAGIELLOŃSKI

\section{MIĘDZYKULTUROWA KOMPETENCJA KOMUNIKACYJNA JAKO TRANSGRESJA}

\section{Wstęp}

Nie tylko kryzys zbyt statycznie i przystosowawczo zorientowanych teorii kompetencji międzykulturowych, ale nade wszystko wyzwania coraz bardziej współzależnych, powiązanych i przenikających się procesów i rzeczywistości społecznych stały się przyczyną koniecznego zwrotu w rozumieniu istoty problemu. Nakładanie się na siebie odmiennych wzorów kultury, systemów wartości i wzrastająca mobilność kultur w wielokulturowym świecie wymusza rozwój nowych kompetencji, które wykraczają poza umiejętność uczenia się standardów kolejnej, spotykanej przez nas kultury w celu głębszego jej rozumienia, przystosowania się i unikania konfliktów. Stąd też przejście, jakie odnotowujemy w koncepcji i praktyce pedagogicznej wielu instytucji edukacji i kultury od koncepcji wielokulturowości do perspektywy między-kulturowej nie jest ani lekceważeniem każdej z zaangażowanych kultur, ani też teorią destrukcyjnej pustki, jaka charakteryzować ma hybrydalny obszar "między” konwencjonalnymi i ustabilizowanymi systemami wartości, treści i identyfikacji. Krytycy koncepcji międzykulturowych ignorują to, co ukazuje procesy, ale i umiejętności wymiany, uczenia się, twórczego projektowania siebie, co pozwala poszerzać wyobraźnię i wrażliwość przedstawicieli różnych kultur o wartości odkryte właśnie w procesach interakcji. „Inter” oznacza wzajemność, otwartość i właśnie wymianę, a termin „akcji” odnosi do podmiotowości, sprawczości i rozwoju z pełnym rozpoznaniem treści będących przedmiotem wymiany. Nie oznacza ona wymieszania, rozmycia, a w skrajnych formach oskarżenia, zdrady wartości kulturowych, które można uznać za „rdzenne”. Procesy takie, które niewątpliwie także mają miejsce, nie są rezultatem inten- 
cjonalnej i świadomej wymiany, ale zagubienia i braku rozumiejącego rozpoznawania oraz podmiotowego traktowania kultur. Są to zupełnie odmienne procesy i jakości obecne w relacjach i dynamice społecznych przeobrażeń. Brak jasnego odróżnienia tych procesów powoduje intelektualny i terminologiczny zamęt, który nie wspiera i nie objaśnia potencjału rozwojowego, jaki jest zawarty w spotkaniach międzykulturowych nie odróżniając ich od wspomnianych zjawisk hybrydyzacji, czy homogenizacji kultury o jakościowo innych cechach, dynamice przebiegu, zaangażowanych typach postaw, a w końcu także rezultatach.

\section{Przyczyny wzrostu znaczenia międzykulturowych kompetencji komunikacyjnych w globalnej przestrzeni kulturowej}

Powstanie nowej przestrzeni dialogu, w której odnajdują się państwa i kultury niezależnie od swojej terytorialnej lokalizacji staje się konsekwencją procesów nieznanych w historii ludzkiej cywilizacji. Przestrzeń ta staje się coraz bardziej bezgraniczna, stanowi efekt nałożenia się wielu bardzo różnych przestrzeni etnicznych, staje się coraz bardziej zróżnicowana. Naturalnym efektem tego nałożenia staje się wzrost interakcji kulturowych, wzajemnych oddziaływań, przenikania, ale także konfliktów i napięć. We wszystkich tych sytuacjach kluczem do rozwiązania narastających wyzwań stają się wspomniane już umiejętności komunikacyjne, ale nie każda komunikacja ma specyficzne cechy dialogu. Aby zrozumieć z czego one wynikają, wymienić musimy procesy, które stanowią o cywilizacyjnym i społecznym kontekście procesów komunikacyjnych.

\section{Mobilność kultur}

Cywilizacja techniczna przyniosła światu, oprócz nowych technologii produkcji, instrumentalizacji wartości i przemodelowania porządku społecznego, zupełnie nowe sposoby przemieszczania towarów, ludzi i informacji, a więc niespotykaną skalę mobilności fragmentów konkretnych przestrzeni kulturowych osadzonych w ramach równie konkretnego terytorium. Konfiguracje tych fragmentów, które tworzą właściwe im przestrzenie, są w stanie ustawicznego ruchu. 
Mobilność kultur powoduje wyraźne przekroczenie ich geograficznych, administracyjnych lub etnicznych granic, szczególnie w wymiarze wytworów kultury symbolicznej. Konwencjonalny związek miejsca, ludzi i ich wytworów zostaje uwolniony i może być skonfigurowany w innych miejscach, ale nade wszystko przemieszczony i zmieniany. Ruch nie tylko w przestrzeni ale całych przestrzeni powoduje, iż zmieniają się sposoby ich definiowania. Uwolnione zostają nie tylko od swego konwencjonalnego miejsca jako swoistej kotwicy i zakorzeniania, ale także od konwencjonalnych związków z pozostałymi komponentami, oraz ich znaczeniami. Przestrzeń i kultura definiowana więc zostaje nie tyle ze względu na owo miejsce, ale względem konfiguracji owych znaczeń, szczególnie jeśli stają się one przedmiotem realnych doświadczeń ludzkich. W ten sposób przemieszczana być może tradycja szkół artystycznych, która podążą za jej wykonawcami i odbiorcami, przestrzeń grup etnicznych, ale także rozproszona przestrzeń odbiorców każdych treści kultury, programów edukacyjnych i informacji.

\section{Deterytorializacja przestrzeni}

Deterytorializacja przestrzeni jest bezpośrednią konsekwencją mobilności kultur i polega na oderwaniu od wspomnianego już miejsca jej wytworzenia, zaistnienia i rozwoju w pierwotnym okresie jej funkcjonowania. Powoduje bezpośrednio nasilenie zróżnicowania przestrzeni kulturowych, ich wieloskładnikowość zarówno ze względu na ich treści, ale także ze względu na ich odmienny charakter. Przestrzeń symboliczna wyposażona we współczesne środki przenoszenia może być rekonstruowania w wielu konfiguracjach. Co istotne, wiele treści kultury zaistnieć może w przestrzeni wirtualnej. Z samej swojej natury ma ona charakter wysoce zdeterytorializowany, a dostęp do niej wynika z reguł dostępu do sieci. Przestrzeń taka przekracza wiele barier, co w istotny sposób wpływa na zasady tworzenia się tożsamości kulturowej, nastawionej znacznie bardziej na jej treści, niż ich terytorialną lokalizację. Można powiedzieć, iż „oś krystalizacji” tożsamości w dobie deterytorializacji kultur ma charakter coraz bardziej abstrakcyjny, coraz mniej „mechaniczny”, bezrefleksyjny, rutynowy. Nie istnieje bowiem gotowy „mechanizm” przypisywania i dawania tożsamości z racji stabilnego miejsca w hierarchii i strukturze społecznej. 


\section{Multiplikacja przestrzeni}

Cywilizacja medialna i najnowsze środki gromadzenia, przetwarzania i przekazu informacji bezpośrednio powodują niespotykane w historii ludzkości możliwości powielania i reprodukcji treści kultury, które po oderwaniu się od swego miejsca powstania zdolne są do replikacji w wielu oddalonych od siebie geograficznie miejscach, w wielu odrębnych bazach cywilizacji „sieci”. Zjawisko to tworzy inny, równie istotny proces ustawicznego poszerzania, a nawet swoistej eksplozji przestrzeni, ponieważ nie istnieje problem zapełnienia i zagospodarowania tych nowych, przestrzennych zdobyczy. Skala multiplikacji jest tak ogromna, iż to ona właśnie wymusza nowe zdobycze poprzez niezwykle agresywne techniki aneksji, zaborczości i konkurencyjnej wręcz walki zwalczających się i ofensywnie działających przestrzeni.

Multiplikacja przestrzeni kulturowych przynosi wiele ubocznych, aczkolwiek logicznie nieuniknionych konsekwencji kulturowego przesycenia nakładającymi się i ustawicznie "gęstniejącymi” pod względem informacyjnym rodzajami przestrzeni. Tożsamość kulturowa znajduje się w stanie „zatopienia” poddana zmasowanemu atakowi procesów przemieszczania, wykorzeniania i multiplikacji. Na wielką próbę wystawione zostają jej zdolności selekcyjne, konstrukcyjne i projektujące. Paradoksalnie nadprodukcja treści prowadzi do zubożenia kulturowego. Polega ono na wspomnianym już „zatopieniu” i przeciążenie umiejętności integracyjnych, zmuszonych do częstych rekonfiguracji i przewartościowania kanonów kultury. Tożsamość znajduje się w stanie technologicznego oblężenia i wymaga zdecydowanego wsparcia poprzez obronę godności i wartości osoby ludzkiej, która nie jest biokomponentem cywilizacji technicznej. Z drugiej strony konieczne okazują się umiejętności łączenia, poruszania się i przepływu pomiędzy różnymi rodzajami przestrzeni o odmiennym statusie ontologicznym, społecznym i mentalnym. Sytuacja ta stwarza kolejną konieczność przedefiniowania pojęcia kompetencji międzykulturowych i otwieraj na potrzeby dialogu.

\section{Konwergencje i interakcje}

Nakładanie się na siebie intensywnie multiplikowanych przestrzeni musi prowadzić do ich intensywnych interakcji. Dzieje się to zarówno „w poziomie", a więc przestrzeni o silnym korelacie fizycznym, które mają geograficzne 
rodowody miejsca, ale $\mathrm{i}, \mathrm{w}$ pionie”, a więc przestrzeni o różnym charakterze, a więc przestrzeni fizycznej, kulturowej, symbolicznej i wirtualnej, która istnieje w sposób quasi-fizyczny, ciągle trudny do opisania, pomiaru i badania. Interakcje przestrzeni stanowią względnie obiektywny czynnik charakteryzujący wyzwania dialogu międzykulturowego. Czerpie on z nich wszystkich, poszerza zakres swojego „budulca”, ale staje często w obliczu chaosu i zagubienia, sprzeczności i wykluczenia. Przenikanie się wszak tak odmiennych przestrzeni wymusza umiejętność równoległego uczestniczenia w światach, które zaledwie się stykają, w światach pomiędzy którymi trudno się poruszać, choć ta właśnie umiejętność stanowić będzie o kluczowych kompetencjach najbliższych nam, a prawdopodobnie jeszcze w większym stopniu, przyszłych czasów.

Konwergencje i interakcje różnego typu przestrzeni w jeszcze większym stopniu niż opisane powyżej mobilności, multiplikacje i deterytorializacje z jednej strony rozbijają, ale $\mathrm{z}$ drugiej, mobilizują dynamizmy i potrzebę dialogu międzykulturowego w wielości ogarniających nas światów. Różnicowanie wewnętrzne kultur nie oznacza wyłącznie ich hybrydyzacji, określa tylko wielość ich potencjałów. Mogą się one uzupełniać, nie muszą wykluczać.

$\mathrm{Ku}$ dialogowi międzykulturowemu skłaniają także tak zwane logotwórcze dynamizmy kultury, a więc procesy sensotwórcze, które stanowią o istocie każdego spotkania kultur w ich podstawowym antropologicznym wymiarze. Tworzenie i nadawanie ludzkim działaniom, przeżyciom i intencjom tej fundamentalnej orientacji „ku czemus”, „ku celom” i „ku wartościom”, często poprzez projektowanie, modelowanie i wybieranie siebie, społeczności i działań, stanowi o twórczych możliwościach przestrzeni dialogu, jeszcze większe wyzwanie niż kiedykolwiek stało przed człowiekiem. Umiejętność stymulowania dialogu międzykulturowego to także nowy typ kompetencji logotwórczych w przestrzeniach globalnych kultury, a więc w przestrzeniach wieloskładnikowych, zróżnicowanych i konwergentywnych [Korporowicz 2011b: 15-36].

\section{Metamorfozy przestrzeni}

Klasyczna przestrzeń fizyczna zachowuje swoją względną jednorodność, choć także tylko wtedy, gdy myślimy o jej równie fizycznych granicach, a więc zakresie jej obecności wyznaczonym poprzez jeden z jej parametrów. Przestrzeń społeczna nie posiada już tak precyzyjnie wyznaczonych granic, jest bardziej rozciągła, rozproszona, posiada swoje wewnętrzne obszary krystalizacji. To samo dotyczy przestrzeni symbolicznej, a jeszcze bardziej wirtual- 
nej. Fenomenem doby świata współczesnego jest fakt przeistaczania się tych przestrzeni, zatapiania w sobie, przechodzenia jednej w drugą lub wielokrotnie już wspominany fakt współistnienia równoległego. Mamy tu do czynienia ze swoistym dialogiem przestrzeni, w którym budowanie mostów jest szczególnie istotne. $Z$ tej perspektywy bliższe so często do siebie grupy $\mathrm{z}$ różnych kultur, ale tych samych przestrzeni, niż z tych samych przestrzeni, ale odmiennych kultur. Dlatego same przestrzenie stanowić zaczynają nowy rodzaj kultury. Informatyk chiński i polski z pewnością lepiej będą się rozumieć w przestrzeni wirtualnej, niż na bazie swoich kultur etnicznych, co stanowi nowy rodzaj mostu nie tylko technologicznego. Przejścia z jednej przestrzeni w drugą nie będą wszak obojętne dla sposobu istnienia firmy, ale także dla kompetencji i tożsamości organizacyjnej jej pracowników, tworzonych przez nie zespołów, sieci kontaktów i więzi, w tym także osobowych, często mających charakter międzykulturowy. Powstające w tym czasie identyfikacje stanowić będą budulec dla tworzonych, zmienianych, a często rekonfigurowanych tożsamości i związanych z nimi sposobów komunikowania. Metamorfozy przestrzeni powodować będą zmienność odniesień kulturowych i osobowych, ale też i odwrotnie to właśnie tożsamość generować będzie rodzaj przestrzeni i możliwości komunikowania w realiach konkretnych organizacji.

\section{Wirtualizacja i relatywizacja przestrzeni komunikacji i dialogu}

Wtajemniczenie w tajniki uczestnictwa w przestrzeni wirtualnej oraz innych przestrzeniach konwergencji to umiejętność rozpoznawania obszarów odniesienia względem których ustalamy charakter realności rzeczy, działań i strategii dialogu. Ustalenie realności znaczeń ma zasadniczy wpływ na charakter i treść interakcji międzykulturowych w świecie poddanym wirtualizacji. Realność obiektów i wartości nowej przestrzeni nie jest jednak absolutna i ustala ją relacja względem jej nośnika. Zanurzony w wirtualnym świecie człowiek może dostać traumatycznego doświadczenia gdy w nałożonych okularach, słuchawkach i pełnych neurologicznych czujników rękawicach zabraknie nagle elektryczności i system wyłączy się z sieci. Ontologiczne bezpieczeństwo kultury i faktyczne szanse dialogu stają się poważnym problemem i wymagają bezwzględnego odniesienia do osoby ludzkiej i rdzennych wartości konkretnej kultury. 


\section{Potrzeba nowego rozumienia międzykulturowych kompetencji komunikacyjnych w kontekście nowych wyzwań współczesnej kultury informacyjnej}

Informacja towarzyszy ludzkości od zarania dziejów, ale to współczesny rozwój społeczeństwa informacyjnego i związany z nim postęp technologiczny znacznie powiększył obszar i znaczenie kultury informacyjnej oraz jej rolę w kształtowaniu nowego typu kompetencji międzykulturowych jako jednej $\mathrm{z}$ kluczowych kompetencji w warunkach gwałtownego rozwoju cywilizacji technicznej. Wzrost roli i istotności informacji łączy się z powstaniem nowej rzeczywistości społecznej generowanej przez nową przestrzeń informacyjną i związaną z nią ściśle przestrzeń kulturową współczesnej cywilizacji medialnej. Jak nigdy dotąd w długiej i różnorodnej historii ludzkości, podlega ona obecnie wielu procesom transgresji, a więc wykraczaniu poza granice tego, co człowiek dotychczas osiągnął, zagospodarował czy też w inny sposób włączył w zakres swojej aktywności. Obszary te także ulegają istotnemu poszerzeniu. Dzieje się tak przede wszystkim na skutek wspomnianego już postępu technicznego i technologicznego, ale również w wyniku rozwoju symbolicznej wyobraźni i aktywności człowieka, wychodzącej poza „myśli uwięzione”, dotychczasowe wzory interakcji społecznych, komunikacji, kultury organizacyjnej, a także kultury przedsiębiorczości. Wiąże się to poza tym z zapotrzebowaniem na nowe umiejętności i typy „kompetencji”, szczególnie te, które łączą się ze zdolnością wykorzystania strategicznych zasobów nowych form cywilizacji, tj. informacyjnych, ale także niezbędnych do ich użytkowania, przetwarzania i przekazywania umiejętności komunikacyjnych [Dijk 2006; Hargie, Saunders, Dickson 1999; Chemers, Ayman 1993; Batorski, Marody, Nowak 2006]. Związek ten sprawił, że coraz częściej używa się łącznego określenia „kompetencje informacyjno-komunikacyjne", ponieważ sama informacja stała się w dzisiejszych czasach bardziej mobilna, błyskawicznie wchodzi w systemy przekazu i interpretacji, staje się elementem niezwykle dynamicznego obiegu w coraz bardziej poszerzającej się przestrzeni.

Współczesny świat trudno już sobie wyobrazić bez owej mobilności, jaką stworzyła rzeczywistość wirtualna. Potrzeba, a nawet konieczność swobodnego przepływ danych czy informacji już nikogo nie dziwi. Przesyłanie ich na dowolną odległość, $\mathrm{w}$ dowolnym czasie, $\mathrm{w}$ dowolne miejsce stało się tak powszechne i oczywiste, że nikt fenomenu tego nie uważa za coś zadziwiającego, choć jeszcze do niedawna proces ten wymagał wielkiego wysiłku, nowych konceptualizacji i organizacji pracy. Człowiek poruszający się obecnie w rzeczywistości łączącej 
elementy realne i wirtualne, przebywa w przestrzeni, w której doświadcza ciągłych, niekończących się strumieni zmiennych zdarzeń, a zachodzące w niej procesy stają się istotą powstawania nowych form mobilności o niespotykanej dotąd strukturze, rolach i funkcjach. Przepływy te, lecz także, co może nawet ważniejsze, interakcje, stwarzają ludziom w XXI wieku nowe możliwości. Nie wystarcza już nam transmisja informacji wyłącznie w jednym, niezmiennym kierunku. Potrzeby rozwojowe powodują zainteresowanie wielostronną wymianą, dzieleniem się, wzajemnością w przekazie informacji, a więc właśnie możliwościami interaktywnego istnienia informacji w procesach uczenia się, wzajemnych akomodacji, synergii systemowych, kulturowych i mentalnych jako symptomu nowych kryteriów rozwoju. Bez wątpienia rodzą się w ten sposób także nieznane dotąd rodzaje ryzyka, często też zagrożenia, niepewności, a nawet zagubienia.

Nowy obszar aktywności ludzkiej wyznacza nowe formy przestrzeni, w tym współczesną przestrzeń informacyjną, dla których trudno znaleźć jednoznaczne definicje czy choćby określenia, wymykają się one bowiem opisowi w kategoriach parametrów fizycznych (odległości między jej nośnikami) Informacje przekazywane są ponad wieloma tradycyjnie pojmowanymi granicami, a sama informacja powstaje w interakcji i oddziaływaniu wielu podmiotów, stając się częścią dynamicznych, często wirtualnych i w istotny sposób „odcieleśnionych” procesów komunikacji. Połączenie elementów klasycznych i wirtualnych $\mathrm{w}$ przestrzeni informacyjnej generuje potrzebę ponownego określenia rozumienia i znaczenia kultury informacyjnej, a w związku z tym również bezpośrednio z nią związanych kompetencji informacyjno-komunikacyjnych, których ewolucja w znacznym stopniu przyczynia do nowego ujęcia pokrewnych im kompetencji międzykulturowych. Informacja nigdy bowiem nie istnieje poza światem kultury, jest pełna znaczeń, a te z natury rzeczy wykazują wielką zmienność, wchodzą w rozmaite konfiguracje o mniej lub bardziej uspołecznionym zasięgu, są przedmiotem wielu negocjacji i wspomnianych wcześniej interakcji. Poszerzenie przestrzeni informacyjnej siłą rzeczy musi doprowadzić do ich nakładania się, a więc zetknięcia, a czasami konfliktu w zakresie sposobu interpretacji, dekodowania i zastosowania (immanentna cecha systemów kulturowych), tym samym zaś do tworzenia międzykulturowych relacji. Zauważenie i analiza tego związku jest jednym z ważnych celów realizowanego badania. W praktyce oznacza to demitologizację czysto technokratycznego traktowania zasobów informacyjnych jako wymykających się transformacyjnemu wpływowi kultur i w swoisty sposób kulturowo „neutralnych”. Taki stosunek do informacji jest efektem bardzo ofensyw- 
nej praktyki i często agresywnej promocji wiedzy informatycznej, która zawiera wiele kulturowych redukcji. Jakiekolwiek jednak jej zastosowanie społeczne natychmiast ujawnia istnienie szerzej pojętej kultury informacyjnej. To ona sprawia, że informacje stają się czymś więcej niż bodźcami i sygnałami, i są nie tylko impulsem o fizycznej charakterystyce, lecz również nośnikiem znaczeń, komponentem obdarzonych sensem struktur i procesów, stają się elementem ludzkiego doświadczenia - zarówno indywidualnego, jak i społecznego - i nabierają właściwych wartości. Wcielone w praktykę działania społecznego zyskują nowe funkcje i potencjał. Wszystkie te procesy przenoszą się sferę relacji międzykulturowych modelując stosowne rodzaje kompetencji.

\section{Rysunek 1.}

Zmiana zakresu kompetencji komunikacyjnych

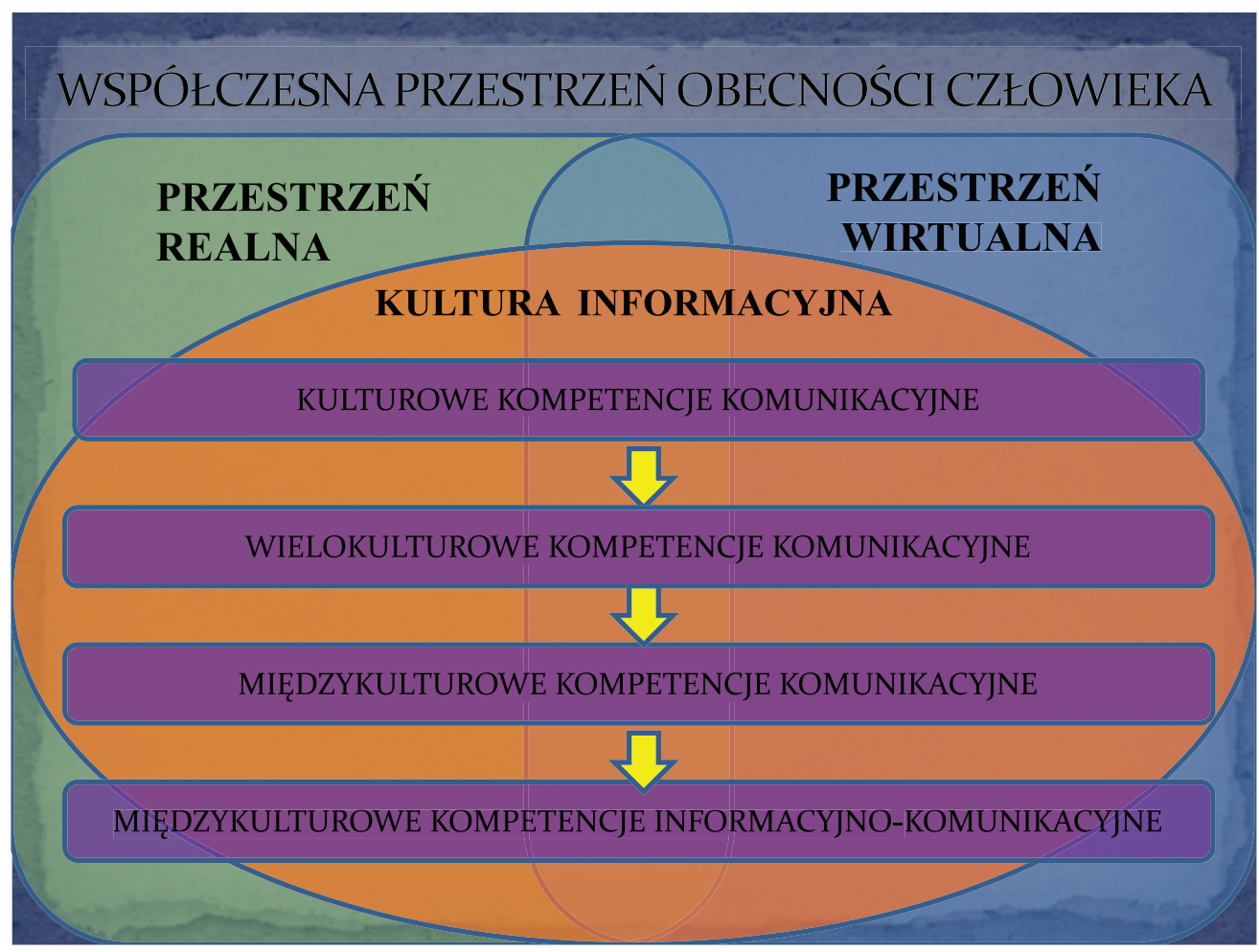

Źródło: opracowanie własne.

Dzisiejszego świata wirtualizacji i medializacji kultur nie można rozpatrywać w kategorii nieruchomego stanu; nie jest to sztywny quasi-obiekt, lecz 
ciągły, niekończący się strumień zmiennych zdarzeń. Zachodzące w nim procesy o różnej intensywności i tempie stają się podstawą generowania nowych form mobilności o niespotykanym dotąd nasileniu, a także strukturze, rolach i funkcjach. Jest to świat narastających interakcji, które będą wchodziły w obszar bezpośrednich kompetencji wielu nieprzygotowanych do tego grup, instytucji i osób - choć poczynając od mobilnych tożsamości, tworzonych często w oderwaniu od własnego "ja” i wolnych od zazwyczaj ścisłej kontroli ego i superego, poprzez mobilne relacje (związki), a na mobilnych i wirtualnych formach istnienia (uczestnictwa) kończąc. To wszystko ma kluczowe znaczenia dla współczesnego rozumienia kompetencji informacyjno-komunikacyjnych i kompetencji międzykulturowych, w przestrzeni wirtualnej bowiem te pierwsze stają się podstawowym warunkiem umiejętnego korzystania z jej zasobów oraz do łączenia elementów wirtualnych z realnymi, te drugie zaś są niezbędne w sytuacji spotkań i interakcji kultur. Dochodzi do nich równie często jak w przestrzeni realnej, a może nawet częściej, choć istota różnic kulturowych jest tu często pomniejszana. Dodatkowo zmieniający się charakter procesów międzykulturowych, realizujący bez ograniczeń ludzkie aspiracje związane z potrzebami wychodzenia poza granice własnej kultury, wymaga jeszcze intensywniejszego, pogłębionego i refleksyjnego kształtowania umiejętności bycia i funkcjonowania na pograniczach kulturowych, intelektualnych, psychicznych, społecznych, politycznych.

W analizach kompetencji informacyjnych i międzykulturowych, szczególnie tych bardziej zaawansowanych, które trzeba będzie koniecznie podjąć w dalszych opracowaniach, należy rozróżnić kompetencje o charakterze powierzchniowym i głębokim, poprzez odwołanie się do takich właśnie form komunikowania. Tradycja ta zbudowana została w latach sześćdziesiątych przez pionierskie studia Noama Chomsky'ego w obszarze koncepcji gramatyk transformacyjno-generatywistycznych [Chomsky 1982; Piattelli-Palmarini 1979]. Skutecznie obaliły one behawioralne paradygmaty pojmowania procesów uczenia się i zbudowały podwaliny twórczego, transgresyjnego rozumienia kompetencji językowych, tak bardzo potrzebne dzisiaj do równie dynamicznego ujęcia tych o charakterze informacyjno-komunikacyjnych, choć już w formie poszerzonej przez twórców kompetencji komunikacyjnych i kulturowych. Transformacyjny komponent kompetencji nabiera szczególnego znaczenia w jej funkcjach transgresyjnych, a więc wtedy, gdy odkrywanie, uczenie się i posługiwanie istniejącymi wzorami kultury, wymaga zasadniczego przebudowania i odnalezienia innej reguły postrzegania, selekcji i konfiguracji ich treści, sposobu ich interpretacji i wartościowania. 


\section{Kompetencje od ujęcia behawioralnego do transgresyjnego}

Odmiennie doświadczane są nie tylko elementy w przestrzeni wirtualnej. Redefinicji wymagają także zachodzące tu czynności, aby za ich pomocą móc analizować szybkie tempo zmian, które się dokonują w typie współczesnego uczestnictwa w kulturze. Konieczność przedefiniowania pojęć wymuszona jest również przez współczesną dynamikę przekształceń społecznych i kulturowych oraz sprzężonych z nimi technologii. W nawiązaniu do przedstawionej powyżej analizy pojęcia kultury informacyjnej przeanalizujmy konieczność modyfikacji rozumienia kompetencji informacyjnej, w kierunku sygnalizowanych potrzeb ujęcia transgresyjnego.

Ewolucja współczesnego społeczeństwa informacyjnego wymusza również przeobrażenia w kompetencjach informacyjnych, które zmieniają swój charakter, przechodząc od statyki do dynamiki, od zamkniętego do otwartego zespołu umiejętności, od budowania ich struktury do uczenia się procesu jej przekształceń, od koncentracji na treści do skupienia się na sposobach ich wykorzystania, wielorakiej przemiany i wdrożenia w zmieniające się realia rzeczywistości. Coraz rzadziej potrzebne jest dzisiaj ujęcie kompetencji informacyjnych jako stabilnych struktur, czyli stanu umiejętności wyszukiwania, ewaluacji i wykorzystywania informacji, które pozwalają jednostce na dostosowanie własnego działania do warunków wyznaczonych przez zmienne otoczenie. Owa przemiana zmierza $\mathrm{w}$ kierunku kompetencji rozumianych procesualnie, gdzie uznaje się transgresyjny potencjał podmiotu, przyjmując, iż generowane przez jednostkę typy działań związane z wyszukiwaniem, przechowywaniem, organizowaniem, przetwarzaniem i wdrażaniem informacji podatne są na twórczą modyfikację występującą jako konsekwencja dynamicznych zmian otoczenia oraz rozwoju osobowego człowieka. 


\section{Tabela 1}

Zmiana charakteru kompetencji komunikacyjnych

\begin{tabular}{|l|l|}
\hline \multicolumn{1}{|c|}{$\begin{array}{c}\text { KOMPETENCJE STRUKTURALNE } \\
\text { (STATYCZNE) }\end{array}$} & \multicolumn{1}{c|}{$\begin{array}{c}\text { KOMPETENCJE TRANSGRESYJNE } \\
\text { (DYNAMICZNE) }\end{array}$} \\
\hline $\begin{array}{l}\text { Uczenie się i praktykowanie istniejących wzo- } \\
\text { rów komunikacji }\end{array}$ & $\begin{array}{l}\text { Uczenie się zmiany istniejących oraz wygene- } \\
\text { rowanych wzorów komunikacji }\end{array}$ \\
$\begin{array}{l}\text { Dostosowanie własnego działania do warun- } \\
\text { ków wyznaczanych przez wymogi istniejącego } \\
\text { otoczenia }\end{array}$ & $\begin{array}{l}\text { Aktywizowanie transgresyjnego potencjał } \\
\text { podmiotu, przyjmując, iż generowane przez } \\
\text { jednostkę typy działań są efektem twórczej } \\
\text { modyfikacji i synergii konkretnych wzorów } \\
\text { jako konsekwencja dynamicznych zmian } \\
\text { otoczenia }\end{array}$ \\
\hline
\end{tabular}

Źródło: opracowanie własne.

Klasyczne rozumienie kompetencji informacyjnej polegało na umiejętności dostosowania się do wzorów kultury, istniejących systemów wartości zachowań. Takie podejście zdawało jednak egzamin w sytuacji, w której istniały względnie stabilne wzory. W okresie dynamicznych zmian nie może ona już polegać na dostosowaniu się, lecz na umiejętności rekompozycji i poszukiwania nowych wzorów. Tym samym zmienia się rozumienie kompetencji: ze zdolności dostosowywania na zdolność eksploracji, i staje się ona czymś twórczym. W ten sposób przechodzimy od koncepcji kompetencji ujmowanej strukturalnie i statycznie do kompetencji pojmowanej dynamicznej. Zmiana ta generuje jednak sposób rozumienia ich rozwoju, co niesie wiele konsekwencji pedagogicznych i szkoleniowych.

\section{Tabela 2}

Implikacje w rozumieniu rozwoju kompetencji komunikacyjnych

\begin{tabular}{|l|l|}
\hline \multicolumn{1}{|c|}{$\begin{array}{c}\text { KOMPETENCJE STRUKTURALNE } \\
\text { (STATYCZNE) }\end{array}$} & \multicolumn{1}{c|}{$\begin{array}{c}\text { KOMPETENCJE TRANSGRESYJNE } \\
\text { (DYNAMICZNE) }\end{array}$} \\
\hline $\begin{array}{l}\text { Rozwój jako wzrost ilościowy przyswojonych } \\
\text { wZorów komunikacji } \\
\text { Motywacja adaptacyjna }\end{array}$ & $\begin{array}{l}\text { Rozwój jako konfigurowanie i struktu- } \\
\text { ralna kombinacja wzorów i sposobów } \\
\text { komunikowania } \\
\text { Motywacja transgresyjna }\end{array}$ \\
\hline
\end{tabular}

Źródło: opracowanie własne. 
Opisane powyżej zmiany wywołane przeobrażeniami współczesnego świata, odcinającego się od statycznego układu, bardzo wolno przekształcających się uwarunkowań i zbliżającego się do mobilnych, zmiennych struktur wytworzyły również nowy model działania i kompetencji człowieka. Dzisiejsza przestrzeń funkcjonowania generuje transgresyjny model ludzkiej aktywności charakteryzujący się zdolnością do systematycznego i świadomego przebudowywania kompetencji już zdobytych, odchodząc tym samym od modelu adaptacyjnego [Glinka, Jelonek 2010; Brown 1998; Paleczny 2007; Mikułowski Pomorski 2007]. Kompetencje informacyjne nie mogą być utożsamiane z raz wyuczonymi i opanowanymi umiejętnościami, których zakres i charakter jest stały.

Częsty błąd w literaturze to opisany wcześniej brak zdolności odróżniania kompetencji informacyjnych od informatycznych, dotyczących znacznie węższego pola umiejętności. To nierzadko ma także wpływ na nierozumienie kompetencji informacyjnych w ich nowym, transgresyjnym znaczeniu, ze względu na zbyt technokratyczne podejście, a więc dalekie od interaktywnych, procesualnych i twórczych skojarzeń. Warto przy tym zaznaczyć, że nadrzędnym terminem, który łączy wszystkie te dywagacje, jest pojęcie kultury informacyjnej. Ono najlepiej wspomaga potrzebę redefinicji wielu zbyt statycznie, behawioralnie i adaptatywnie rozumianych określeń opisujących innowacyjne działania w warunkach systemowej zmiany ustroju gospodarczego, ale także mentalnych, kulturowych i edukacyjnych transformacji współczesnej polskiej rzeczywistości. Kultura informacyjna jest także zapleczem wielu innych kompetencji, w tym, rozważanych tu, międzykulturowych, istotnych nie tylko w relacjach czysto symbolicznych, lecz także w bardzo pragmatycznych stosunkach gospodarczych (industrial relations). Prawdopodobnie dopiero w nadchodzącej dekadzie nauki społeczne podejmą analizę tych wszystkich zależności i sformułują zarówno nowe pojęcia, jak i pragmatyczne instrukcje pod adresem działań szkoleniowych, edukacyjnych i badawczych o różnym zasięgu, które odpowiadać będą rodzącym się - nie tylko w Polsce - nowym potrzebom kooperacji międzynarodowej w epoce zaawansowanych technologii. Angażują one wiedzę instrumentalną i technokratyczną, ale także antropologiczną, kulturową, a nawet filozoficzną, szczególnie wtedy, gdy „borykamy” się z rozumieniem starych, jak i zupełnie nowych pojęć.

\section{WNIOSKI}

W uwarunkowaniach nieograniczonej mobilności kultur, świata który pokonuje nieprzekraczalne do tej pory granice, coraz silniej odczuwamy potrzebę 
edukacji nie tyle wielokulturowej, co międzykulturowej, w więc takiej, w której dochodzi do intensywnych interakcji kultur, ich wzajemnego współistnienia, ale i konfliktów, współdziałania, ale i konkurencji. Wyzwaniem wielu nauk oraz systemów edukacji staje się pogłębianie charakteru tych kontaktów na konstruktywnie rozumiejący, z bezrefleksyjnego na krytyczny, z wrogiego na dialogiczny.

Dotychczasowe rozważania naukowców koncentrowały się na edukacji międzykulturowej zachodzącej w tradycyjnej, realnej przestrzeni. Współczesna gidensowska „epoka oszałamiającej zmiany” wprowadzając nowy wirtualny wymiar obecności człowieka, coraz częściej skłania do refleksji nad przebiegiem procesów oddziaływania kultur w wirtualnej przestrzeni, która wymusza także nowe typy kompetencji. Łatwość z jaką uczestnicy Internetu nawiązują kontakty międzykulturowe jest zadziwiająca i można byłoby postawić pytanie czy w ogóle jest tu potrzebna edukacja międzykulturowa, skoro uczestnictwo $\mathrm{w}$ różnych kulturach przebiega tu w sposób niewymuszony, a nawet zadziwiająco naturalny.

Współcześnie nie chodzi już tylko o poznanie zwyczajów innych ludzi, i nie tylko o uświadomienie odmienności różnych nacji ale o umiejętność pokonywania tych różnic, budowania komunikacyjnych mostów pozwalających na kreatywne poszukiwanie zdolności wzajemnego zrozumienia, a następnie porozumienia, a więc obszarów współpracy, empatii i efektywnego uczenia się. Edukacji międzykulturowej przypada w związku z tym duża rola w pogłębianiu szacunku do 'innych" i jednocześnie do siebie, wzajemne poznawanie, kreowanie porozumienia $\mathrm{w}$ interakcjach, umacnianie znaczenia różnorodności rozumianej nie tylko jako źródło dysfunkcji, ale i rozwoju, a tym samym kształtowania podstaw tolerancji i wzajemnego uznania, również w wymiarze wirtualnym. Pedagogika charakteryzując się złożonością i wielowymiarowością objaśniania świata, nie ogranicza się wyłącznie do poznania rzeczywistości, zawiera w sobie potencjał jej zmiany. $Z$ tych powodów fundamentalnego wręcz znaczenia nabierają rozwojowe, transgresyjne aspekty kompetencji w co najmniej w trzech, dających się wyodrębnić obszarach, które implikują odmienne strategie edukacyjne. 


\section{Tabela 3}

Edukacyjne implikacje odmiennego ujęcia międzykulturowych kompetencji komunikacyjnych

\begin{tabular}{|l|l|}
\hline \multicolumn{1}{|c|}{$\begin{array}{c}\text { KOMPETENCJE STRUKTURALNE } \\
\text { (STATYCZNE) }\end{array}$} & KOMPETENCJE TRANSGRESYJNE \\
(DYNAMICZNE)
\end{tabular}

Źródło: opracowanie własne.

Strategia przetrwania w warunkach ustawicznej zmiany wymaga więc czegoś więcej niż mogliśmy do tej pory przypuszczać. Nawet ona, nie mówiąc już o strategii rozwoju, musi coraz częściej odwoływać się do kompetencji oswajania filozofii zmiany, uczenia się szukania, a nie powielania, moderowania, a nie perswadowania, liderowania, a nie kontrolowania, odkrywania, a nie egzekwowania. Rodzi to oczywiście wiele nowych i niełatwych pytań o konieczne źródła tak niecodziennych umiejętności, ich zasoby oraz praktyczne sposoby wdrażania. Z pewnością nie można będzie na nie odpowiedzieć w ramach jednej, nawet najbardziej abstrakcyjnej nauki, co określa horyzonty rozwojowe współczesnej nauki oraz jej kluczowej misji. 


\section{Bibliografia}

Batorski D., Marody M., Nowak A. (red.), (2006), Społeczna przestrzeń Internetu, Warszawa Brown A. (1998), Organizational Culture, London

Castells M. (2003), Galaktyka Internetu. Refleksje nad Internetem, biznesem i społeczeństwem, Poznań

Chemers M.M., Ayman R. (red.), (1993), Leadership Theory and Research. Perspectives and Directions, London, New York

Chomsky N. (1982), Zagadnienia teorii składni, przekł. I. Jakubczak. Wrocław

Curry A., Moore C. (2003), Assessing information culture - an exploratory model, „International Journal of Information Management" nr (23)

Duszak A. (1998), Tekst, dyskurs, komunikacja międzykulturowa, Warszawa

Furmanek W. (2002), Kultura techniczna i kultura informacyjna. Eksplikacja pojęcia. Konsekwencje metodologiczne, [w:] J. Morbitzer (red.), Techniki komputerowe w przekazie edukacyjnym. Kraków

Glinka B., Jelonek A. (red.), (2010). Zarządzanie międzykulturowe, Kraków

Hargie O., Saunders Ch., Dickson D. (1999), Social Skills in Interpersonal Communication, New York

Jaskuła S. (2012a), New Forms of Mobility in the Word of Virtualization and Medialization of Cultures, [w:] L. Korporowicz (red.), Mobility of Cultures, „Politeja”, The Journal of the Faculty of Political and International Studies of the Jagiellonian University, 20/1, Kraków Jaskuła S. (2012b), Symbioza i odrębność dwóch światów, [w:] S. Jaskuła, L. Korporowicz (red.), Współczesna przestrzeń tożsamości, „Politeja”, Pismo Studiów Międzynarodowych i Politycznych Uniwersytetu Jagiellońskiego, nr 20/2, Kraków

Jaskuła S. (2011a), Wykluczenie $w$ międzykulturowej przestrzeni informacyjnej, [w:] T. Lewowicki, A. Szczurek-Boruta, J. Suchodolska (red.) Pedagogika międzykulturowa wobec wykluczenia społecznego i edukacyjnego, Cieszyn - Warszawa - Toruń

Jaskuła S. (2011b), Przestrzeń informacyjna jako przestrzeń edukacyjna, [w:] A. Cudowska (red.), Kierunki rozwoju edukacji w zmieniającej się przestrzeni społecznej, Białystok

Jaskuła S. (2011c), Intercultural space. Contemporary challenges and perspectives, [w:] S. Abudayeh, K. Bojko (red.) Poland - Jordan - European Union: Future Aspects, Amman, Jordan

Jaskuła S., Korporowicz L. O potrzebie redefinicji pojęcia kompetencji informacyjnych i międzykulturowych (w druku)

Jaskuła S., Korporowicz L. (2012), Kultura informacyjna w zarzadzaniu międzykulturowym. Ujęcie transgresyjne [w:] I. Sobieraj (red.), Kompetencje informacyjno-komunikacyjne $i$ międzykulturowe w gospodarce. Od adaptacji do innowacji, Warszawa

Kłoskowska A. (2005), Kultury narodowe u korzeni, Warszawa

Korporowicz L. (2011a), Tożsamość kulturowa w przestrzeni międzykulturowej, [w:] L. Korporowicz (red.), Socjologia kulturowa, Kraków

Korporowicz L. (2011b), Logotwórcze dynamizmy kultury, [w:] L. Korporowicz (red.), Socjologia kulturowa, Kraków

Korporowicz L. (2011c), Edukacja jako interakcja. Rozwojowe dylematy współczesnego społeczeństwa wiedzy, [w:] A. Cudowska (red.), Kierunki rozwoju edukacji w zmieniającej się przestrzeni społecznej, Białystok 
Korporowicz L. (2010a), Podmioty przestrzeni międzykulturowej, [w:] J. Zdanowski, E. Rekłajtis, R. Wiśniewski (red.), Jedność i różnorodność. Kultura vs. kultury, Warszawa

Korporowicz L. (2010b), Kultury $w$ działaniu. O twórczym potencjale dziedzictwa i komunikacji, [w:] S. Partycki (red.), Partnerstwo i wspótpraca a kryzys gospodarczo - społeczny $w$ Europie Srodkowej i Wschodniej, t. 1, Lublin

Korporowicz L. (2009), Komunikacja symboliczna w rozwoju tożsamości kulturowej, [w:] L. Dyczewski (red.), Tożsamość polska w odmiennych kontekstach, Lublin

Krzysztofek K., Szczepański M. S. (2002), Zrozumieć rozwój. Od społeczeństw tradycyjnych do informacyjnych, Katowice

Levinson P. (2006), Miękkie ostrze, czyli historia i przyszłość rewolucji informacyjnej, przekł. H. Jankowska, Warszawa

Martin V.A., Lycett M., Macredie R. (2003), Exploring the gap between business and IT: an information culture approach. Referat wygłoszony na Konferencji ALOIS 2003, Linköping, Sweden, 12-13 March, http://www.vits.org/konferenser/alois2003/html/6895.pdf [1.10.2011]

May Ch. (2002), The Information Society. A Sceptical View, Cambridge

Mikułowski Pomorski J. (2007), Jak narody porozumiewaja się ze soba $w$ komunikacji międzykulturowej i komunikowaniu medialnym, Kraków

Paleczny T. (2007), Interpersonalne stosunki międzykulturowe, Kraków

Piattelli-Palmarini M. (red.), (1979), Language and Learning. Debate between Jan Piaget and Noam Chomsky. Cambridge, Massachusets

Piątek T. (2003). Potrzeba badań kultury informacyjnej, [w:] W. Furmanek, W. Walat (red.), Teoretyczne i praktyczne problemy edukacji technicznej i informatycznej, Rzeszów

Ramirez E. (2003), Reading, information literacy, and information culture. Referat wygłoszony na Międzynarodowej Konferencji Information Literacy Experts, Prague, http://www.infolit.org/International_Conference/papers/ramirez-fullpaper.pdf [1.10.2011].

Van Dijk J. (2006), The Network Society, London

Widén-Wulff G. (2000), Business information culture: a qualitative study of the information culture in the Finnish insurance business, Information Research, 5 


\section{SUMMARY}

\section{Intercultural communicative competence as transgression}

The contemporary multicultural world, characterized by the overlapping of different cultural patterns, value systems and the increasing mobility of cultures, forces the development of new competencies. The innovation extends beyond the ability to learn the standards of another culture we encounter, to understand it more deeply, to adapt to it and avoid conflicts. Today's human space presence generates a transgressive model of human activity, characterized by the ability to rebuild a systematic and conscious competence, already acquired, thus moving away from the model of adaptive competence in the direction of competence understood processually, where transgressive potential of the subject is recognised.

\section{Keywords:}

intercultural communication competence, transgressive competency model, a structural model of competence, communication processes, information culture 